\title{
Treatment of Advanced Prostate Cancer-A Review of Current Therapies and Future Promise
}

\author{
Semini Sumanasuriya and Johann De Bono \\ Division of Clinical Studies, The Institute of Cancer Research, Drug Development Unit, The Royal Marsden NHS \\ Foundation Trust, Sutton, Surrey SM2 5PT, United Kingdom \\ Correspondence: johann.de-bono@icr.ac.uk
}

\begin{abstract}
Despite many recent advances in the therapy for metastatic castration-resistant prostate cancer (mCRPC), the disease remains incurable, although men suffering from this disease are living considerably longer. In this review, we discuss the current treatment options available for this disease, such as taxane-based chemotherapy, the novel hormone therapies abiraterone and enzalutamide, and treatments such as radium-223 and sipuleucel-T. We also highlight the need for ongoing research in this field, because, despite numerous recent advances, the prognosis for mCRPC remains poor. Furthermore, as a growing body of evidence shows the increasing heterogeneity of the disease, and highlights the ongoing need for disease molecular stratification and validation/qualification of predictive biomarkers, we explore this burgeoning research space that is likely to transform how we treat this disease. We describe putative predictive biomarkers, including androgen receptor splice variants, phosphatase and tensin homolog (PTEN) loss, homologous recombination repair defects, including BRCA2 loss, and mismatch repair defects. The development of next-generation sequencing techniques and the routine biopsy of metastatic disease have driven significant advances in our understanding of the genomics of cancer, and are now poised to transform our treatment of this disease.
\end{abstract}

$\mathrm{D}$ espite many recent advances in the therapy for metastatic castration-resistant prostate cancer (mCRPC), the disease remains incurable, although men suffering from this disease are living considerably longer. In this review, we discuss the current treatment options available and highlight the need for ongoing research in this field.

Standard treatment for mCRPC, with androgen deprivation by either orchiectomy or luteinizing hormone-releasing hormone (LHRH) therapy, remains effective in improving both disease prognosis and symptoms (Lorente et al.
2015). However, suppressing testosterone offers disease control for only an average of 18 to 36 months before the disease enters the castrationresistant phase (Petrylak et al. 2004; Lam et al. 2006). Once the disease is no longer castration sensitive, further treatment is needed, with the aim of increasing overall survival (OS) and, perhaps more importantly, improving symptoms and promoting quality of life. In this review, we discuss the current treatment options available for patients with advanced disease, and explore the relative advantages and disadvantages of approved treatments, including chemothera-

Editors: Michael M. Shen and Mark A. Rubin

Additional Perspectives on Prostate Cancer available at www.perspectivesinmedicine.org

Copyright (C) 2018 Cold Spring Harbor Laboratory Press; all rights reserved; doi: 10.1101/cshperspect.a030635

Cite this article as Cold Spring Harb Perspect Med 2018;8:a030635 
py, novel hormone therapies such as abiraterone and enzalutamide, as well as radium-223 and sipuleucel-T. We also highlight the need for ongoing research in this field, because, despite these numerous recent advances, the prognosis for mCRPC remains poor. Furthermore, as a growing body of evidence shows the increasing interpatient heterogeneity of the disease (Robinson et al. 2015), we explore the increasing need for disease molecular stratification, describing putative predictive biomarkers, including androgen receptor splice variants (AR-SVs), phosphatase and tensin homolog (PTEN) loss, and homologous recombination (HR) repair defects, including BRCA2 loss and mismatch repair (MMR) defects.

\section{CURRENTLY AVAILABLE TREATMENT OPTIONS}

Here, we discuss the currently available treatment options for advanced disease. At the time of writing, no preferred sequence of treatment has been established (Fitzpatrick and de Wit 2014). Treatment decisions should be made by the patient's treating clinician, in conjunction with the patient and their family, as well as with the input of a multidisciplinary team. It also depends substantially on patient preference, current symptoms, and burden of disease, as well as local availability. With all treatments, patients should be monitored closely for evidence of clinical, biochemical, and radiological progression (biochemical monitoring alone is inadequate). If the patient is not participating in a clinical trial, these can be performed at the physician's discretion. However, baseline scans and repeat imaging every 3-6 months are highly recommended (Scher et al. 2016) because a major challenge remains in determining the optimal timing of treatment switch decisions.

\section{Chemotherapy}

\section{Docetaxel}

Docetaxel chemotherapy was the first treatment to show an improvement in OS in MCRPC following two landmark phase III trials. These trials showed improvement in OS, symptoms, prostate-specific antigen (PSA), and quality of life of mCRPC patients treated with docetaxel and prednisolone versus mitoxantrone and prednisolone (Tannock et al. 2004; Berthold et al. 2008). This survival benefit was seen across all age groups, and, following these studies, an established regimen of three weekly intravenous docetaxel for 10 cycles is given as first-line chemotherapy.

Taxanes exert their anticancer activity by targeting microtubules during mitosis and interphase, and causing stabilization of the mitotic spindle leading to arrest of mitosis and cell proliferation, ultimately causing cell death (Azarenko et al. 2014). The mechanism of action is not fully understood; taxanes are also thought to have some antiandrogenic properties, potentially being able to block nuclear translocation of the androgen receptor (AR), which is also microtubule dependent (Gan et al. 2009; Zhu and Kyprianou 2010; Darshan et al. 2011; van Soest et al. 2013; Fitzpatrick and de Wit 2014). A phase III trial performed in 2003, TAX327, confirmed that a PSA decline of $\geq 50 \%$ occurred in $45 \%$ of patients treated with docetaxel with prednisolone with a median OS of 19.2 months (Berthold et al. 2008). The benefits of prednisone/prednisolone in this regimen remain, however, controversial and there are increasing concerns about iatrogenic steroids being able to drive disease resistance.

Docetaxel is administered intravenously every 3 weeks for a recommended 10 cycles (Seruga and Tannock 2011), although again the optimal treatment duration is not well defined and merits further evaluation. This is usually at a dose of $75 \mathrm{mg} / \mathrm{m}^{2}$, although dose reductions can be introduced depending on tolerability. Side effects experienced are similar to those seen with many other types of chemotherapy, including nausea, vomiting, and cytopenias, with some patients experiencing subsequent neutropenic sepsis. Docetaxel (Sanofi-Aventis) use is also associated with both motor and sensory peripheral neuropathy, which can develop with cumulative doses. Retreatment with docetaxel, especially in patients whose tumors have never been determined to be refractory to this agent bears further evaluation for men with dis- 
ease recurrence, especially if more than 6 months of remission have elapsed since previous docetaxel exposure. With docetaxel now being used also for treatment-naïve metastatic disease at diagnosis, retreatment for progressing mCRPC also needs further evaluation and may still lead to patient benefit.

\section{Cabaxitaxel}

The other approved chemotherapy for treatment of mCRPC is the semisynthetic taxane, cabazitaxel, which exerts a similar mechanism of action, causing cell death by disruption of microtubule function (Vrignaud et al. 2014). Cabazitaxel was selected to overcome the emergence of taxane resistance and has been shown to have antitumor activity in both the postdocetaxel and chemotherapy-naïve setting and to exert antitumor activity in docetaxel-resistant cancers (Pivot et al. 2008). Following the results of the phase III TROPIC trial, this drug was granted approval by the Food and Drug Administration (FDA) in 2010, as a second-line treatment following docetaxel. This trial confirmed important efficacy activity of cabazitaxel with a survival advantage when combined with prednisolone compared to the drug mitoxantrone with prednisolone (de Bono et al. 2010).

Two further phase III studies have confirmed the efficacy of cabazitaxel, including FIRSTANA, which examined whether cabazitaxel at two doses $\left(20 \mathrm{mg} / \mathrm{m}^{2}\right.$ or $\left.25 \mathrm{mg} / \mathrm{m}^{2}\right)$ was superior to docetaxel $75 \mathrm{mg} / \mathrm{m}^{2}$ in terms of OS in chemotherapy-naïve mCRPC patients. This FDA-mandated trial was the first study in CRPC to compare two life-prolonging therapies (Tannock et al. 2004; de Bono et al. 2010), and did not show superiority for OS of cabazitaxel $\left(20 \mathrm{mg} / \mathrm{m}^{2}\right.$ or $25 \mathrm{mg} / \mathrm{m}^{2}$ ) versus docetaxel in the 1178 patients treated. Progression-free survival and PSA response did not differ significantly across treatment arms, although tumor responses were significantly higher for cabazitaxel $25 \mathrm{mg} / \mathrm{m}^{2}$ versus docetaxel (Sartor 2016). In this trial, cabazitaxel at $20 \mathrm{mg} / \mathrm{m}^{2}$ was best tolerated. The PROSELICA study was a phase III noninferiority study of cabazitaxel $20 \mathrm{mg} / \mathrm{m}^{2}$ versus cabazitaxel $25 \mathrm{mg} / \mathrm{m}^{2}$ in $1200 \mathrm{mCRPC}$ patients who had all been previously treated with docetaxel (de Bono 2016). The results from this FDA-mandated trial confirmed the previously reported antitumor activity of cabazitaxel in patients previously treated with docetaxel. The trial also met the predefined noninferiority end point, indicating that a reduced dose of $20 \mathrm{mg} /$ $\mathrm{m}^{2}$ of cabazitaxel maintained at least $50 \%$ of the OS benefit of $25 \mathrm{mg} / \mathrm{m}^{2}$.

Cabazitaxel is administered similarly to docetaxel, via an intravenous infusion given once every 3 weeks. Based on the above trials, the standard dose remains $25 \mathrm{mg} / \mathrm{m}^{2}$, and this higher dose does appear more active. However, this can now be confidently reduced to $20 \mathrm{mg} / \mathrm{m}^{2}$ in selected patients, for example, those with a decreased performance status or who experience toxicity such as neutropenic sepsis or are unable to tolerate the side-effect profile. Side effects experienced for cabazitaxel are similar to those with docetaxel, and most commonly include neutropenia, nausea, fatigue, and diarrhea (Heidenreich et al. 2013; Wissing et al. 2013a; Bracarda et al. 2014). Concomitant steroids and antiemetics are given prophylactically to minimize side effects. Chemotherapy-induced peripheral neuropathy is much less common with cabazitaxel, with symptoms ranging from numbness in the peripheries and cold insensitivity to pain and loss of balance. The current recommendation is also for up to 10 cycles of cabazitaxel to be administered, provided the patient is tolerating the treatment well and does not show evidence of clinical, biochemical, or radiological progression (Galsky et al. 2010), although the optimal duration of treatment with this agent remains poorly defined.

\section{Mitoxantrone}

The FDA initially approved mitoxantrone in 1996 for palliative treatment in mCRPC when a small phase III trial showed some antitumor activity and symptomatic relief, but without significant survival benefit in unselected patients (Tannock et al. 1996). Retrospective analyses of data from phase III randomized controlled trials, including mitoxantrone in a treatment arm, have confirmed evidence of symptomatic 
improvement without survival benefit in unselected patients (Green et al. 2015). Mitoxantrone is associated with significant toxicity, including pancytopenias, fatigue, and shortness of breath (Green et al. 2015). Despite this, physicians still use it, albeit rarely, for symptom control in patients in whom treatment options may otherwise be limited. Mitoxantrone is, however, a type II topoisomerase inhibitor that impacts DNA synthesis and DNA repair and is likely to be most active in prostate cancers with DNA repair defects. Further studies evaluating whether mitoxantrone is most active against prostate cancer with defects in DNA repair mediated by $\mathrm{HR}$ are now warranted.

\section{Novel Hormone Therapies}

It is well established that androgen signaling plays a pivotal role in both hormone-sensitive prostate cancer and $\mathrm{mCRPC}$. Several aberrations of the AR have been identified in MCRPC, including gene amplification, overexpression, rearrangements, splice variants, and activating mutations. These aberrations likely contribute to persistent AR signaling despite castrate levels of testosterone. Identification of compounds targeting this pathway has provided us with several drugs of important clinical significance, including abiraterone and enzalutamide, which now both have regulatory approval (Scher et al. 2010; de Bono et al. 2011). Furthermore, as both drugs are orally available and generally well tolerated, the ease of administration makes them a preferred option for many patients.

The formation of AR splice variants (of which AR-V7 is the most studied) appears to be a major factor contributing to castration resistance. These variants, which have been associated with resistance to abiraterone and enzalutamide (Antonarakis et al. 2014), lack the ligand-binding domain of the $\mathrm{AR}$, but remain constitutionally active. It has been shown that AR-V7 expression is higher in patients with advanced prostate cancer after castration and even more after abiraterone/enzalutamide, and that higher levels associate with treatment resistance and poor prognosis (Efstathiou et al. 2015; Welti et al. 2016). However, further prospective work exploring the significance of AR splice variants, including AR-V7 with agents targeting these, are needed for further validation. Critically, analytically validated and practical assays to determine the presence of these splice variants are now urgently needed to establish this putative predictive biomarker.

\section{Abiraterone}

Abiraterone acetate is an irreversible, selective cytochrome p450 17A1 (CYP17) inhibitor that blocks steroid conversion and therefore androgen production within the prostate, testis, and adrenal gland (Attard et al. 2005). Several large phase III studies have confirmed the antitumor activity of abiraterone as an effective treatment for men suffering from CRPC (de Bono et al. 2011; Fizazi et al. 2012; Ryan et al. 2012) with improvement in OS of almost 5 months in the postchemotherapy setting. Preclinical data indicate that abiraterone acetate is metabolized to generate a potent $\mathrm{AR}$ antagonist that is at least as potent at blocking AR as enzalutamide, which suggests that this agent not only blocks CYP17 but also AR directly (Li et al. 2015, 2016).

Abiraterone is orally available and taken at a dose of $1000 \mathrm{mg} /$ day, in combination with a low dose of oral prednisolone. In approximately one-third of patients, a "steroid switch" from prednisolone to low-dose dexamethasone at the point of progression showed reversal of resistance, with patients showing durable PSA and radiological responses following the change in steroids. The rationale behind this treatment switch is secondary to abiraterone resistance being the result of AR point mutations activated by prednisolone but not dexamethasone, as well as glucocorticoid receptor activation, which is also lower with dexamethasone (Lorente et al. 2014). Common side effects of abiraterone are linked to increased mineralocorticoid levels induced by CYP17 blockade, and include hypertension, hypokalemia, and fluid retention (Fizazi et al. 2012). Low-dose oral steroids such as prednisone/prednisolone $5 \mathrm{mg}$ twice daily or dexamethasone $0.5 \mathrm{mg} /$ day can abrogate these side effects. The latter may indeed be preferable be- 
cause it has a longer half-life and is less likely to activate the mineralocorticoid receptor, or mineralocorticoid receptor antagonists that do not bind the AR such as eplerenone can be used. The mineralocorticoid antagonist spironolactone is an AR agonist and must be avoided in this patient population. There is also a small risk of transaminase elevation with abiraterone treatment and, consequently, liver function should be monitored in the first 12 weeks.

\section{Enzalutamide}

Enzalutamide (MDV3100) (Tran et al. 2009) is a novel antiandrogen that offers a treatment advantage over standard antiandrogens antagonizing full-length $\mathrm{AR}$ and preventing $\mathrm{AR}$ nuclear translocation, AR binding to DNA, and coactivator recruitment by AR. Large phase III trials (including AFFIRM and PREVAIL) have shown significant antitumor activity with improvement in OS in both the pre- and postchemotherapy settings (Scher et al. 2012; Beer et al. 2014).

Enzalutamide is taken orally, once daily, at a dose of $160 \mathrm{mg}$. Common side effects include fatigue, gastrointestinal disturbance, and hot flushes. More serious, rarer side effects include seizures, which have been reported in $<1 \%$ of patients treated with enzalutamide (HoffmanCensits and Kelly 2013) and may be as infrequent as impacting $0.1 \%$ of patients. Enzalutamide does appear to potently penetrate the blood-brain barrier and has been reported to significantly cause neurocognitive deficits and significant fatigue, although these are usually reversible.

\section{Abiraterone versus Enzalutamide}

Superiority of either drug has not as of yet been shown, and patient preference and comorbidities play a large role in treatment choice. Abiraterone is best avoided in patients with cardiovascular disease because of the mineralocorticoid side effects listed above. Similarly, because of the risk of seizures, treatment with enzalutamide is not advised in patients who have preexisting structural brain damage or known seizure activity. Moreover, in patients with jobs requiring substantial intellectual engagement, abiraterone may be preferable to enzalutamide. A recent randomized trial reports an increased prevalence of these side effects in patients on enzalutamide (Chi 2016). Overall, however, both of these drugs are generally well tolerated.

Some studies have shown evidence that a small number of patients do respond to abiraterone post-enzalutamide, and indeed to enzalutamide post-abiraterone, but these figures have been much lower than predicted, with response rates in the region of 10\% to $15 \%$ (Loriot et al. 2013; Schrader et al. 2014). This is likely caused by cross-resistance between these agents (Fizazi et al. 2012) and the formation of AR splice variants (Mostaghel et al. 2011). Lower response rates mean that, in many health-care settings, treatment with either abiraterone or enzalutamide is not currently approved if the patient has already received the other novel endocrine agent (enzalutamide or abiraterone).

\section{Radium-223}

Radium-223, also known as alpharadin, is a radioisotope that emits high-energy alpha particles over a short range $(<100 \mu \mathrm{m})$; these induce double-strand DNA breaks in adjacent tumor cells, while sparing normal tissue without a significant bystander effect. The phase III ALSYMPCA trial (alpharadin in symptomatic prostate cancer) showed a significant improvement in OS (of almost 3 months) compared with treatment with placebo from radium-223. Radium-223 also delayed symptomatic skeletal events and improved quality of life (Parker et al. 2013).

Radium is given as four weekly intravenous infusions for a total of six cycles (Parker et al. 2013), although the optimal dose, schedule, and duration of treatment with this agent is not yet well defined. Because of its highly localized activity, radium-223 has a favorable side-effect profile and is generally well tolerated. Common side effects seen include fatigue, gastrointestinal disturbance, and bone pain. Hematological toxicity, including anemia, thrombocytopenia, and leucopenia, can be seen due to effects on adjacent bone marrow. However, this is usually mild and can be treated with supportive treatment 
until the bone marrow recovers (Wissing et al. 2013b).

Although the highly targeted therapy that alpharadin delivers is beneficial in terms of side effects, it is important to remember that eligibility for ALSYMPCA included only symptomatic mCRPC patients with bony metastases and no visceral disease (Sartor et al. 2014). Therefore, radium-223 is not a recommended treatment for patients who have disease outside of their skeleton, that is, nodal $(>3 \mathrm{~cm}$ in shortaxis) or visceral metastases or large volume soft tissue disease. Developments in alpha-particleemitting radioimmunoconjugates are likely to further transform the treatment of advanced prostate cancer, for example, with antibodies to prostate-specific membrane antigen (PSMA) linked to alpha particles emitting radioisotopes showing a huge potential for patient benefit. The usage of gallium-PSMA positron-emitting-tomography (PET) may be a useful predictive biomarker for these agents (Kratochwil et al. 2016).

\section{Sipuleucel-T}

Sipuleucel-T is currently the only form of immunotherapy approved for the treatment of $\mathrm{mCRPC}$, and the first therapeutic cancer vaccine to be approved by the FDA. This is an autologous dendritic cell vaccine whereby a patient's peripheral blood mononuclear cells, including antigen-presenting cells, are initially extracted by leukapheresis. These are then activated ex vivo with a fusion protein (PA202), which contains prostate acid phosphatase and granulocyte macrophage colony-stimulating factor. The activated product is then infused back into the patient, and this infusion triggers the patient's own immune response into attacking their disease (Di Lorenzo et al. 2012). Several positive studies have indicated that this agent has antitumor efficacy, including a small phase III trial that showed an improvement in OS of more than 4 months in patients randomized to sipuleucel-T versus placebo (Kantoff et al. 2010), although some concerns have been raised about the design of this trial (Huber et al. 2012). Questions regarding its efficacy and side-effect profile, as well as high cost because of the expensive cost-of-production (estimated at $\sim \$ 35,000$ per cycle [Simpson et al. 2015]), have meant that this drug has not been widely used.

Based on evidence from clinical trials, the FDA-recommended dosage should be for three complete doses to be given via infusion at approximately 2 -week intervals. Side effects include those associated with the initial leukapheresis procedure to harvest the patient's mononuclear cells (e.g., bleeding, bruising, and light-headedness), the infusion (e.g., rigors and pyrexia), and treatment itself (commonly fatigue, nausea, and headache) (Kantoff et al. 2010; Small et al. 2013).

\section{SYMPTOMATIC THERAPY}

Although the therapies discussed above all offer a degree of survival benefit, it is vital to remember that symptom control is of paramount importance. Patients should have input from their community palliative care team as early as possible, and ideally this must be part of the overall multidisciplinary care team (Bader et al. 2012; Scotté 2012). Other medical interventions, such as blood transfusions for symptomatic anemia and radiotherapy for painful bony metastases, must also be regularly considered. Finally, in patients with metastatic disease at diagnosis who never get their prostate primary treated early in the treatment process, due consideration needs to be given to local control as early as possible to abrogate potentially devastating local complications such as urinary obstruction and fistulae formation (Donovan et al. 2016). Randomized phase III trials such as STAMPEDE have evaluated whether local therapy in patients with M1 disease at diagnosis impacts outcome and quality of life; the results of these studies are eagerly awaited but in the interim the treatment of the primary disease must not be forgotten in this subgroup of patients with aggressive disease.

\section{FUTURE THERAPIES}

Unfortunately, the prognosis of mCRPC patients and their OS rates, despite these recent advances in treatment, remain bleak. Although there are a plethora of treatments now available 
for mCRPC, realistically these agents all provide only relatively small survival benefits. It has been recognized that the landscape of prostate cancer is evolving; increased understanding of the heterogeneity of the disease and the identification and validation of predictive biomarkers would allow optimization of treatment with patientspecific targeted therapies (Lorente et al. 2015; Robinson et al. 2015).

The development of next-generation sequencing techniques have driven significant advances in our understanding of the genomics of cancer and allowed for novel therapies to be developed. Robinson et al. (2015) showed the mutational landscape of $\mathrm{mCRPC}$ by performing whole-exome and transcriptome sequencing of biopsy specimens from 150 mCRPC patients. Many oncogenic mutations were identified in the vast majority of patients, including those affecting the AR pathway (63\%), PI3K pathway (49\%), and DNA repair pathway (23\%), to name but a few. Actionable aberrations were identified in the vast majority of patients, and the importance of performing fresh biopsies in patients was shown, as many of these mutations had not been present in their primary prostate cancers (Gundem et al. 2015). Identification of actionable biomarkers in the metastatic setting could allow for precision medicine, that is, patient-specific targeted therapy to be administered with the goal of improving prognosis. Distinguishing between actionable aberrations allows us to better explore further treatment options.

\section{PTEN/AKT Pathway}

It is widely accepted that many patients with mCRPC ( $\sim 50 \%)$ have activation of the PI3K/ AKT pathway, which plays a vital role in tumor growth, proliferation, and survival, and also in resistance to therapy (Bellacosa et al. 2005; Manning and Cantley 2007). Functional loss of PTEN, a protein that down-regulates this pathway, is thought to be present in $>40 \%$ of metastatic prostate cancers, because of gene deletions, methylation, micro-RNA (miRNA) expression, mutations, and posttranslational modifications (Yoshimoto et al. 2012). It has also been shown that PTEN loss is associated with advanced dis- ease and poor outcome (Ayala et al. 2004; Reid et al. 2010; Yoshimoto et al. 2012; Ferraldeschi et al. 2015). Furthermore, studies have shown cross talk between the PI3K pathway and AR signaling, showing that PTEN loss results in increased AKT activation and up-regulation of AR signaling through p110 $\beta$ (Carver et al. 2011; Schwartz et al. 2015). These studies, and others, have provided a strong rationale for developing combination strategies targeting this pathway. Preclinical and phase I studies have been conducted to test single-agent AKT inhibitors, with modest results thus far (Chen et al. 2006; Dienstmann et al. 2011). The reasons for this are likely multifactorial, and include cross talk between signaling pathways and tumor heterogeneity. This highlights the need for further trials exploring combination therapies, which are currently ongoing, combining $\mathrm{p} 110 \beta$ and AKT inhibitors with next-generation AR antagonists, including abiraterone and enzalutamide.

\section{DNA Repair Pathway}

Mutations in DNA repair have also been identified in MCRPC, and have important clinical implications. It is now well established that genes involved in $\mathrm{HR}$, including $B R C A 2, B R C A 1$, $P A L B 2$, and $A T M$ are commonly deleteriously aberrant in this disease. It has also been reported that patients with deleterious germline BRCA2 mutations are at increased risk of prostate cancer (Struewing et al. 1997; Gallagher et al. 2010). Additionally, germline BRCA 1 and BRCA $2 \mathrm{mu}$ tations are associated with both higher grade and stage of cancer at diagnosis, and worse outcomes (Gallagher et al. 2010; Castro et al. 2015). MMR defects have also been reported in this disease, with Lynch syndrome carriers of deleterious aberrations of MMR genes also associating with increased prostate cancer risk (Pritchard et al. 2014; Ryan et al. 2014). These DNA repair defects open a therapeutic avenue with immunotherapy strategies (Graff et al. 2016).

\section{PARP Inhibition}

Targeting cancers with defects in HR repair has also opened doors for the treatment of MCRPC. 
A trial reported in 2015 showed the antitumor activity of olaparib, a poly(adenosine diphosphate $[\mathrm{ADP}]$-ribose) polymerase (PARP) inhibitor, in patients with both somatic and germline aberrations in BRCA and other genes involved in HR DNA repair (Mateo et al. 2015). PARP is an enzyme that is key to DNA repair, and PARP enzyme inhibition has already been established as a treatment for ovarian cancers, with studies showing durable objective responses and improvement in progression-free survival in sporadic high-grade serous ovarian cancers (Gelmon et al. 2010; Ledermann et al. 2012). This study by Mateo and colleagues in mCRPC patients enrolled 50 patients with late-stage disease (all of whom had received prior docetaxel and either abiraterone or enzalutamide, as well as a further $58 \%$ having also received cabazitaxel), who were treated with olaparib monotherapy. Of the 49 evaluable patients, 16 responded to olaparib, with 12 receiving the drug for more than 6 months. Overall, $88 \%(14 / 16)$ of the responders were found to have defects in DNA-repair genes (including both biallelic somatic loss and germline mutations of BRCA2, as well as ATM mutations) (Mateo et al. 2015). The study has led to the FDA granting "breakthrough" designation in January 2016 to support the accelerated approval of olaparib for monotherapy of BRCA1, BRCA2, or ATM-gene-mutated mCRPC patients.

Olaparib is given orally in tablet form, and is generally well tolerated. Known side effects include hematological toxicity, with anemia being both the most common adverse event reported and the main reason for dose reductions in the TOPARP trial, in which $400 \mathrm{mg}$ of this PARP inhibitor was administered twice daily to patients. Other toxicities, including fatigue, nausea, vomiting, and decreased appetite, have also been reported (Fong et al. 2009).

\section{Platinum-Based Chemotherapy}

Although not currently approved for treatment of mCRPC, phase II trials that include platinumbased chemotherapy in unselected mCRPC patients have shown antitumor activity (Sella et al. 2009; Hager et al. 2016). Platinum salts have, in some ways, similar mechanisms of action to PARP inhibitors, causing double-stranded DNA damage by inducing inter- and intrastrand DNA cross-links. This DNA damage and resultant tumor cell death have been shown to induce PSA and radiological response in patients, as well as increased progression-free survival to some degree in unselected patients. However, failure to optimally identify a target group may, at least in part, explain failed registration trials. A phase III trial with satraplatin, an orally bioavailable platinum compound, showed evidence of second-line antitumor activity in unselected patients, with a $50 \%$ PSA decline rate of $33 \%$ and significant progression-free survival rates in $40 \%$ of the patients (Sternberg et al. 2009). It is likely that if this trial was repeated in prostate cancer patients with DNA repair defects, then this trial would result in a survival benefit.

In ovarian cancer, the prevalence of aberrations in genes involved in HR confer sensitivity to both platinum and PARP inhibition, and patients who progress following PARP inhibition may still respond to platinum. Furthermore, it has been reported that ovarian cancer patients with nucleotide excision repair (NER) pathway defects respond to platinum while displaying PARP inhibitor resistance (Ceccaldi et al. 2015). NER defects may also be found in mCRPC, and further phase II and III studies testing the safety and efficacy of platinum-based chemotherapy in selected groups of biomarkerpositive patients with differing DNA repair pathway aberrations are warranted.

Platinum chemotherapy, such as 3-weekly carboplatin given intravenously (e.g., at AUC6 or AUC5 dosage) needs further evaluation in mCRPC patients with defects in HR and in other DNA-repair pathways; preliminary data indicate that this has antitumor activity (Cheng et al. 2016). Platinum-associated side effects include hematological toxicity and nephrotoxicity, alopecia, mucositis, nausea, and vomiting (Fotopoulou et al. 2014).

\section{Mismatch Repair Defects}

In addition to defects in $\mathrm{HR}$ repair, other forms of DNA repair, including MMR, have been im- 
Treatment of Advanced Prostate Cancer

plicated in $\mathrm{mCRPC}$, with the prevalence of MMR aberrations estimated to be in the region of $3 \%-12 \%$, depending on assay selection (Pritchard et al. 2014; Robinson et al. 2015). MMR protein loss of function (e.g., caused by mutations in MLH1, MLH2, MSH6) is associated with microsatellite instability and high mutational load. High-mutation frequency is thought to result in a higher burden of neoepitopes or neoantigens, which are tumor specific and allow for enhanced immune recognition. Targeting immune checkpoints, for example, inhibiting CTLA4 and PD-1, may therefore up-regulate the body's immune response (Snyder et al. 2014). A positive association has been found between tumors high in PD-L1 and total mutation load in several tumor types (Ock et al. 2016). Using immunotherapy to block the PD-1 axis is already established for the treatment of various tumor types, with nivolumab (anti-PD1) and pembrolizumab (anti-PD1) having been approved by the FDA for the treatment of melanoma and nonsmall-cell lung cancer (NSCLC) (Herbst et al. 2014; Tumeh et al. 2014; Robert et al. 2015; Van Allen et al. 2015). Frequent somatic mutations are a result of ultraviolet light exposure in melanoma and cigarette smoking in NSCLC. Studies have shown that in these tumor types, increased likelihood of response associates with mutational load, which can associate with the presence of deleterious DNA repair defects (Rizvi et al. 2015). Moreover, MMR loss was associated with treatment benefit from pembrolizumab in colorectal carcinomas (Le et al. 2015).

The prevalence of MMR-defective advanced prostate cancer may be higher than that described in some reports, as many studies characterizing them thus far have used whole-exome or targeted sequencing, although MMR defects in MCRPC have been shown to be commonly associated with intronic rearrangements (Pritchard et al. 2014). As higher mutational load is also associated with other DNA repair defects (Le et al. 2015), there is now a strong rationale for evaluating immunotherapy and combination strategies for targeting this subset of mCRPC.

\section{CONCLUSIONS}

This review has highlighted the challenges of treatment in the evolving landscape of mCRPC. Despite the development of several well-tolerated and efficacious treatments, these diseases remain invariably fatal, although patients are living longer than ever before. The patient and physician should make treatment decisions together, with the latter working in the context of multidisciplinary teams using all currently available evidence. Where possible, next-generation sequencing-based tumor analyses should be pursued because these are highly likely to identify specific genomic aberrations that can guide patient care. We envision that over the next decade, the treatment of advanced prostate cancer diseases will change substantially, allowing the delivery of better and more precise care for this disease.

\section{ACKNOWLEDGMENTS}

We thank Prostate Cancer UK, the Movember Foundation, The Prostate Cancer Foundation, Cancer Research UK, the Medical Research Council, and Stand Up to Cancer for their support. We acknowledge all the staff in the Prostate Cancer Targeted Therapy Group at the Royal Marsden Hospital and the Cancer Biomarkers Team at The Institute of Cancer Research as well as all our patients and their families.

\section{REFERENCES}

Antonarakis ES, Lu C, Wang H, Luber B, Nakazawa M, Roeser JC, Chen Y, Mohammad TA, Chen Y, Fedor HL et al. 2014. AR-V7 and resistance to enzalutamide and abiraterone in prostate cancer. N Engl J Med 371: 10281038.

Attard G, Belldegrun AS, de Bono JS. 2005. Selective blockade of androgenic steroid synthesis by novel lyase inhibitors as a therapeutic strategy for treating metastatic prostate cancer. BJU Int 96: 1241-1246.

Ayala G, Thompson T, Yang G, Frolov A, Li R, Scardino P, Ohori M, Wheeler T, Harper W. 2004. High levels of phosphorylated form of Akt-1 in prostate cancer and non-neoplastic prostate tissues are strong predictors of biochemical recurrence. Clin Cancer Res 10: 6572-6578.

Azarenko O, Smiyun G, Mah J, Wilson L, Jordan MA. 2014 Antiproliferative mechanism of action of the novel taxane cabazitaxel as compared with the parent compound do- 
cetaxel in MCF7 breast cancer cells. Mol Cancer Ther 13: 2092-2103.

Bader P, Echtle D, Fonteyne V, Livadas K, De Meerleer G Paez Borda A, Papaioannou EG, Vranken JH. 2012. Prostate cancer pain management: EAU guidelines on pain management. World J Urol 30: 677-686.

Beer TM, Armstrong AJ, Rathkopf DE, Loriot Y, Sternberg $\mathrm{CN}$, Higano CS, Iversen P, Bhattacharya S, Carles J, Chowdhury S, et al. 2014. Enzalutamide in metastatic prostate cancer before chemotherapy. $N$ Engl J Med 371: 424-433.

Bellacosa A, Kumar CC, Di Cristofano A, Testa JR. 2005. Activation of AKT kinases in cancer: Implications for therapeutic targeting. Adv Cancer Res 94: 29-86.

Berthold DR, Pond GR, Soban F, de Wit R, Eisenberger M, Tannock IF. 2008. Docetaxel plus prednisone or mitoxantrone plus prednisone for advanced prostate cancer: Updated survival in the TAX 327 study. J Clin Oncol 26: 242-245.

Bracarda S, Gernone A, Gasparro D, Marchetti P, Ronzoni M, Bortolus R, Fratino L, Basso U, Mazzanti R, Messina C, et al. 2014. Real-world cabazitaxel safety: The Italian early-access program in metastatic castration-resistant prostate cancer. Future Oncol 10: 975-983.

Carver BS, Chapinski C, Wongvipat J, Hieronymus H, Chen Y, Chandarlapaty S, Arora VK, Le C, Koutcher J, Scher H, et al. 2011. Reciprocal feedback regulation of PI3K and androgen receptor signaling in PTEN-deficient prostate cancer. Cancer Cell 19: 575-586.

Castro E, Goh C, Leongamornlert D, Saunders E, Tymrakiewicz M, Dadaev T, Govindasami K, Guy M, Ellis S, Frost D, et al. 2015. Effect of BRCA mutations on metastatic relapse and cause-specific survival after radical treatment for localised prostate cancer. Eur Urol 68: 186-193

Ceccaldi R, O'Connor KW, Mouw KW, Li AY, Matulonis UA, D'Andrea AD, Konstantinopoulos PA. 2015. A unique subset of epithelial ovarian cancers with platinum sensitivity and PARP inhibitor resistance. Cancer Res 75: 628-634.

Chen ML, Xu PZ, Peng X, Chen WS, Guzman G, Yang X, Di Cristofano A, Pandolfi PP, Hay N. 2006. The deficiency of Akt1 is sufficient to suppress tumor development in Pten $^{+/}$mice. Genes Dev 20: 1569-1574.

Cheng HH, Pritchard CC, Boyd T, Nelson PS, Montgomery B. 2016. Biallelic inactivation of $B R C A 2$ in platinum-sensitive metastatic castration-resistant prostate cancer. Eur Urol 69: 992-995.

Chi KN. 2016. Proceedings of ASCO 2016. Chicago, IL.

Darshan MS, Loftus MS, Thadani-Mulero M, Levy BP, Escuin D, Zhou XK, Gjyrezi A, Chanel-Vos C, Shen R, Tagawa ST, et al. 2011. Taxane-induced blockade to nuclear accumulation of the androgen receptor predicts clinical responses in metastatic prostate cancer. Cancer Res 71: 6019-6029.

de Bono JS. 2016. Proceedings of ASCO 2016. Chicago, IL.

de Bono JS, Oudard S, Ozguroglu M, Hansen S, Machiels JP, Kocak I, Gravis G, Bodrogi I, Mackenzie MJ, Shen L, et al. 2010. Prednisone plus cabazitaxel or mitoxantrone for metastatic castration-resistant prostate cancer progressing after docetaxel treatment: A randomised open-label trial. Lancet 376: 1147-1154. de Bono JS, Logothetis CJ, Molina A, Fizazi K, North S, Chu L, Chi KN, Jones RJ, Goodman OB, Saad F, et al. 2011. Abiraterone and increased survival in metastatic prostate cancer. N Engl J Med 364: 1995-2005.

Dienstmann R, Rodon J, Markman B, Tabernero J. 2011. Recent developments in anti-cancer agents targeting PI3K, Akt and mTORC1/2. Recent Pat Anticancer Drug Discov 6: 210-236.

Di Lorenzo G, Ferro M, Buonerba C. 2012. Sipuleucel-T (Provenge) for castration-resistant prostate cancer. BJU Int 110: E99-E104.

Donovan JL, Hamdy FC, Lane JA, Mason M, Metcalfe C, Walsh E, Blazeby JM, Peters TJ, Holding P, Bonnington S, et al. 2016. Patient-reported outcomes after monitoring, surgery, or radiotherapy for prostate cancer. $N$ Engl J Med 375: 1425-1437.

Efstathiou E, Titus M, Wen S, Hoang A, Karlou M, Ashe R, Tu SM, Aparicio A, Troncoso P, Mohler J, et al. 2015. Molecular characterization of enzalutamide-treated bone metastatic castration-resistant prostate cancer. Eur Urol 67: 53-60.

Ferraldeschi R, Nava Rodrigues D, Riisnaes R, Miranda S, Figueiredo I, Rescigno P, Ravi P, Pezaro C, Omlin A, Lorente D, et al. 2015. PTEN protein loss and clinical outcome from castration-resistant prostate cancer treated with abiraterone acetate. Eur Urol 67: 795-802.

Fitzpatrick JM, de Wit R. 2014. Taxane mechanisms of action: Potential implications for treatment sequencing in metastatic castration-resistant prostate cancer. Eur Urol 65: 1198-1204.

Fizazi K, Scher HI, Molina A, Logothetis CJ, Chi KN, Jones RJ, Staffurth JN, North S, Vogelzang NJ, Saad F, et al. 2012. Abiraterone acetate for treatment of metastatic castration-resistant prostate cancer: Final overall survival analysis of the COU-AA-301 randomised, double-blind, placebo-controlled phase 3 study. Lancet Oncol 13: $983-$ 992.

Fong PC, Boss DS, Yap TA, Tutt A, Wu P, Mergui-Roelvink M, Mortimer P, Swaisland H, Lau A, O'Connor MJ, et al. 2009. Inhibition of poly(ADP-ribose) polymerase in tumors from BRCA mutation carriers. N Engl J Med 361: 123-134.

Fotopoulou C, Vergote I, Mainwaring P, Bidzinski M, Vermorken JB, Ghamande SA, Harnett P, Del Prete SA, Green JA, Spaczynski M, et al. 2014. Weekly AUC2 carboplatin in acquired platinum-resistant ovarian cancer with or without oral phenoxodiol, a sensitizer of platinum cytotoxicity: The phase III OVATURE multicenter randomized study. Ann Oncol 25: 160-165.

Gallagher DJ, Gaudet MM, Pal P, Kirchhoff T, Balistreri L, Vora K, Bhatia J, Stadler Z, Fine SW, Reuter V, et al. 2010. Germline BRCA mutations denote a clinicopathologic subset of prostate cancer. Clin Cancer Res 16: 2115-2121.

Galsky MD, Dritselis A, Kirkpatrick P, Oh WK. 2010. Cabazitaxel. Nat Rev Drug Discov 9: 677-678.

Gan L, Chen S, Wang Y, Watahiki A, Bohrer L, Sun Z, Wang Y, Huang H. 2009. Inhibition of the androgen receptor as a novel mechanism of taxol chemotherapy in prostate cancer. Cancer Res 69: 8386-8394.

Gelmon KA, Tischkowitz M, Mackay H, Swenerton K, Robidoux A, Tonkin K, Hirte H, Huntsman D, Clemons M, 
Gilks B, et al. 2011. Olaparib in patients with recurrent high-grade serous or poorly differentiated ovarian carcinoma or triple-negative breast cancer: A phase 2, multicentre, open-label, non-randomised study. Lancet Oncol 12: $852-861$.

Graff JN, Alumkal JJ, Drake CG, Thomas G V, Redmond WL, Farhad M, Cetnar JP, Ey FS, Bergan RC, Slottke R, et al. 2016. Early evidence of anti-PD-1 activity in enzalutamide-resistant prostate cancer. Oncotarget 7: 5281052817.

Green AK, Corty RW, Wood WA, Meeneghan M, ReederHayes KE, Basch E, Milowsky MI, Dusetzina SB. 2015. Comparative effectiveness of mitoxantrone plus prednisone versus prednisone alone in metastatic castrate-resistant prostate cancer after docetaxel failure. Oncologist 20: 516-522.

Gundem G, Van Loo P, Kremeyer B, Alexandrov LB, Tubio JMC, Papaemmanuil E, Brewer DS, Kallio HML, Högnäs G, Annala M, et al. 2015. The evolutionary history of lethal metastatic prostate cancer. Nature 520: $353-$ 357.

Hager S, Ackermann CJ, Joerger M, Gillessen S, Omlin A. 2016. Anti-tumor activity of platinum compounds in advanced prostate cancer-A systematic literature review. Ann Oncol 27: 975-984.

Heidenreich A, Scholz HJ, Rogenhofer S, Arsov C, Retz M, Müller SC, Albers P, Gschwend J, Wirth M, Steiner U, et al. 2013. Cabazitaxel plus prednisone for metastatic castration-resistant prostate cancer progressing after docetaxel: Results from the German compassionate-use programme. Eur Urol 63: 977-982.

Herbst RS, Soria JC, Kowanetz M, Fine GD, Hamid O, Gordon MS, Sosman JA, McDermott DF, Powderly JD, Gettinger SN, et al. 2014. Predictive correlates of response to the anti-PD-L1 antibody MPDL3280A in cancer patients. Nature 515: 563-567.

Hoffman-Censits J, Kelly WK. 2013. Enzalutamide: A novel antiandrogen for patients with castrate-resistant prostate cancer. Clin Cancer Res 19: 1335-1339.

Huber ML, Haynes L, Parker C, Iversen P. 2012. Interdisciplinary critique of sipuleucel-T as immunotherapy in castration-resistant prostate cancer. J Natl Cancer Inst 104: 273-279.

Kantoff PW, Higano CS, Shore ND, Berger ER, Small EJ, Penson DF, Redfern CH, Ferrari AC, Dreicer R, Sims RB, et al. 2010. Sipuleucel-T immunotherapy for castration-resistant prostate cancer. $N$ Engl J Med 363: 411422.

Kratochwil C, Bruchertseifer F, Giesel FL, Weis M, Verburg FA, Mottaghy F, Kopka K, Apostolidis C, Haberkorn U, Morgenstern A. 2016. 225Ac-PSMA-617 for PSMA targeting $\alpha$-radiation therapy of patients with metastatic castration-resistant prostate cancer. J Nucl Med 57: 19411944.

Lam JS, Leppert JT, Vemulapalli SN, Shvarts O, Belldegrun AS. 2006. Secondary hormonal therapy for advanced prostate cancer. J Urol 175: 27-34.

Le DT, Uram JN, Wang H, Bartlett BR, Kemberling H, Eyring $\mathrm{AD}$, Skora $\mathrm{AD}$, Luber BS, Azad NS, Laheru D, et al. 2015. PD-1 blockade in tumors with mismatch-repair deficiency. N Engl J Med 372: 2509-2520.
Ledermann J, Harter P, Gourley C, Friedlander M, Vergote I, Rustin G, Scott C, Meier W, Shapira-Frommer R, Safra T, et al. 2012. Olaparib maintenance therapy in platinumsensitive relapsed ovarian cancer. $N$ Engl J Med 366: 1382-1392.

Li Z, Bishop AC, Alyamani M, Garcia JA, Dreicer R, Bunch D, Liu J, Upadhyay SK, Auchus RJ, Sharifi N. 2015. Conversion of abiraterone to D4A drives anti-tumour activity in prostate cancer. Nature 523: 347-351.

Li Z, Alyamani M, Li J, Rogacki K, Abazeed M, Upadhyay SK, Balk SP, Taplin ME, Auchus RJ, Sharifi N. 2016. Redirecting abiraterone metabolism to fine-tune prostate cancer anti-androgen therapy. Nature 533: 547-551.

Lorente D, Omlin A, Ferraldeschi R, Pezaro C, Perez R, Mateo J, Altavilla A, Zafeirou Z, Tunariu N, Parker C, et al. 2014. Tumor responses following a steroid switch from prednisone to dexamethasone in castration-resistant prostate cancer patients progressing on abiraterone. Br J Cancer 111: 2248-2253.

Lorente D, Mateo J, Perez-Lopez R, de Bono JS, Attard G. 2015. Sequencing of agents in castration resistant prostate cancer. Lancet Oncol 16: e279-e292.

Loriot Y, Bianchini D, Ileana E, Sandhu S, Patrikidou A, Pezaro C, Albiges L, Attard G, Fizazi K, De Bono JS, et al. 2013. Antitumor activity of abiraterone acetate against metastatic castration-resistant prostate cancer progressing after docetaxel and enzalutamide (MDV3100). Ann Oncol 24: 1807-1812.

Manning BD, Cantley LC. 2007. AKT/PKB signaling: Navigating downstream. Cell 129: 1261-1274.

Mateo J, Carreira S, Sandhu S, Miranda S, Mossop H, Perez-Lopez R, Nava Rodrigues D, Robinson D, Omlin A, Tunariu N, et al. 2015. DNA-repair defects and olaparib in metastatic prostate cancer. $N$ Engl J Med 373: 1697-1708.

Mostaghel EA, Marck BT, Plymate SR, Vessella RL, Balk S, Matsumoto AM, Nelson PS, Montgomery RB. 2011. Resistance to CYP17Al inhibition with abiraterone in castration-resistant prostate cancer: Induction of steroidogenesis and androgen receptor splice variants. Clin Cancer Res 17: 5913-5925.

Ock CY, Keam B, Kim S, Lee JS, Kim M, Kim TM, Jeon YK, Kim DW, Chung DH, Heo DS. 2016. Pan-cancer immunogenomic perspective on the tumor microenvironment based on PD-L1 and CD8 T-cell infiltration. Clin Cancer Res 22: 2261-2270.

Parker C, Nilsson S, Heinrich D, Helle SI, O'Sullivan JM, Fosså SD, Chodacki A, Wiechno P, Logue J, Seke M, et al. 2013. Alpha emitter radium-223 and survival in metastatic prostate cancer. N Engl J Med 369: 213223.

Petrylak DP, Tangen CM, Hussain MHA, Lara PN, Jones JA, Taplin ME, Burch PA, Berry D, Moinpour C, Kohli M, et al. 2004. Docetaxel and estramustine compared with mitoxantrone and prednisone for advanced refractory prostate cancer. N Engl J Med 351: 1513-1520.

Pivot X, Koralewski P, Hidalgo JL, Chan A, Gonçalves A, Schwartsmann G, Assadourian S, Lotz JP. 2008. A multicenter phase II study of XRP6258 administered as a 1H I.V. infusion every 3 weeks in taxane-resistant metastatic breast cancer patients. Ann Oncol 19: 15471552. 
Pritchard CC, Morrissey C, Kumar A, Zhang X, Smith C, Coleman I, Salipante SJ, Milbank J, Yu M, Grady WM, et al. 2014. Complex MSH2 and MSH6 mutations in hypermutated microsatellite unstable advanced prostate cancer. Nat Commun 5: 4988.

Reid AHM, Attard G, Ambroisine L, Fisher G, Kovacs G, Brewer D, Clark J, Flohr P, Edwards S, Berney DM, et al 2010. Molecular characterisation of ERG, ETV1 and PTEN gene loci identifies patients at low and high risk of death from prostate cancer. Br J Cancer 102: 678-684.

Rizvi NA, Hellmann MD, Snyder A, Kvistborg P, Makarov V, Havel JJ, Lee W, Yuan J, Wong P, Ho TS, et al. 2015. Mutational landscape determines sensitivity to PD-1 blockade in non-small-cell lung cancer. Science 348: 124-128.

Robert C, Schachter J, Long GV, Arance A, Grob JJ, Mortier L, Daud A, Carlino MS, McNeil C, Lotem M, et al. 2015. Pembrolizumab versus ipilimumab in advanced melanoma. N Engl J Med 372: 2521-2532.

Robinson D, Van Allen EM, Wu YM, Schultz N, Lonigro RJ, Mosquera JM, Montgomery B, Taplin ME, Pritchard CC, Attard G, et al. 2015. Integrative clinical genomics of advanced prostate cancer. Cell 161: 1215-1228.

Ryan CJ, Smith MR, De Bono JS, Molina A, Logothetis C, De Souza PL, Fizazi K, Mainwaring PN, Piulats Rodriguez $\mathrm{JM}, \mathrm{Ng}$ S, et al. 2012. Interim analysis (IA) results of COU-AA-302, a randomized, phase III study of abiraterone acetate (AA) in chemotherapy-naive patients (pts) with metastatic castration-resistant prostate cancer (mCRPC). 2012 Annual Meeting of the American Society of Clinical Oncology (ASCO), Abstract LBA4518. Chicago, IL, June 1-5.

Ryan S, Jenkins MA, Win AK. 2014. Risk of prostate cancer in Lynch syndrome: A systematic review and meta-analysis. Cancer Epidemiol Biomarkers Prev 23: 437-449.

Sartor O. 2016. Proceedings of ASCO 2016. Chicago, IL.

Sartor O, Coleman R, Nilsson S, Heinrich D, Helle SI, O'Sullivan JM, Fosså SD, Chodacki A, Wiechno P, Logue J, et al. 2014. Effect of radium-223 dichloride on symptomatic skeletal events in patients with castration-resistant prostate cancer and bone metastases: Results from a phase 3 , double-blind, randomised trial. Lancet Oncol 15: 738746.

Scher HI, Beer TM, Higano CS, Anand A, Taplin ME, Efstathiou E, Rathkopf D, Shelkey J, Yu EY, Alumkal J, et al. 2010. Antitumor activity of MDV3100 in castration-resistant prostate cancer: A phase 1-2 study. Lancet 375: 1437-1446.

Scher HI, Fizazi K, Saad F, Taplin ME, Sternberg CN, Miller K, de Wit R, Mulders P, Chi KN, Shore ND, et al. 2012. Increased survival with enzalutamide in prostate cancer after chemotherapy. $N$ Engl J Med 367: 1187-1197.

Scher HI, Morris MJ, Stadler WM, Higano C, Basch E, Fizazi $\mathrm{K}$, Antonarakis ES, Beer TM, Carducci MA, Chi KN, et al 2016. Trial design and objectives for castration-resistant prostate cancer: Updated recommendations from the prostate cancer Clinical Trials Working Group 3. J Clin Oncol 34: 1402-1418.

Schrader AJ, Boegemann M, Ohlmann CH, Schnoeller TJ, Krabbe LM, Hajili T, Jentzmik F, Stoeckle M, Schrader M,
Herrmann E, et al. 2014. Enzalutamide in castration-resistant prostate cancer patients progressing after docetaxel and abiraterone. Eur Urol 65: 30-36.

Schwartz S, Wongvipat J, Trigwell CB, Hancox U, Carver BS, Rodrik-Outmezguine V, Will M, Yellen P, de Stanchina E, Baselga J, et al. 2015. Feedback suppression of PI3Ko signaling in PTEN-mutated tumors is relieved by selective inhibition of PI3K $\beta$. Cancer Cell 27: 109-122.

Scotté F. 2012. The importance of supportive care in optimizing treatment outcomes of patients with advanced prostate cancer. Oncologist 17: 23-30.

Sella A, Yarom N, Zisman A, Kovel S. 2009. Paclitaxel, estramustine and carboplatin combination chemotherapy after initial docetaxel-based chemotherapy in castrationresistant prostate cancer. Oncology 76: 442-426.

Seruga B, Tannock IF. 2011. Chemotherapy-based treatment for castration-resistant prostate cancer. J Clin Oncol 29: 3686-3694.

Simpson EL, Davis S, Thokala P, Breeze PR, Bryden P, Wong R. 2015. Sipuleucel-T for the treatment of metastatic hormone-relapsed prostate cancer: A NICE single technology appraisal; an evidence review group perspective. Pharmacoeconomics 33: 1187-1194.

Small EJ, Lance RS, Redfern CH, Millard FE, Gardner TA, Karsh LI, Dawson NA, McCoy C, Stubbs A, DeVries T, et al. 2013. A randomized phase II trial of sipuleucel-T with concurrent or sequential abiraterone acetate (AA) plus prednisone $(\mathrm{P})$ in metastatic castrate-resistant prostate cancer (mCRPC). 2013 Annual Meeting of the American Society of Clinical Oncology (ASCO), Abstract 5047. Chicago, IL, May 31-June 4.

Snyder A, Makarov V, Merghoub T, Yuan J, Zaretsky JM, Desrichard A, Walsh LA, Postow MA, Wong P, Ho TS, et al. 2014. Genetic basis for clinical response to CTLA4 blockade in melanoma. $N$ Engl J Med 371: 21892199.

Sternberg CN, Petrylak DP, Sartor O, Witjes JA, Demkow T, Ferrero JM, Eymard JC, Falcon S, Calabrò F, James N, et al. 2009. Multinational, double-blind, phase III study of prednisone and either satraplatin or placebo in patients with castrate-refractory prostate cancer progressing after prior chemotherapy: The SPARC trial. J Clin Oncol 27: 5431-5438.

Struewing JP, Hartge P, Wacholder S, Baker SM, Berlin M, McAdams M, Timmerman MM, Brody LC, Tucker MA 1997. The risk of cancer associated with specific mutations of BRCA1 and BRCA2 among Ashkenazi Jews. $N$ Engl J Med 336: 1401-1408.

Tannock I, Osoba D, Stockler M, Ernst D, Neville A, Moore M, Armitage G, Wilson J, Venner P, Coppin CM, et al. 1996. Chemotherapy with mitoxantrone plus prednisone or prednisone alone for symptomatic hormone-resistant prostate cancer: A Canadian randomized trial with palliative end points. J Clin Oncol 14: 1756-1764.

Tannock IF, de Wit R, Berry WR, Horti J, Pluzanska A, Chi KN, Oudard S, Théodore C, James ND, Turesson I, et al. 2004. Docetaxel plus prednisone or mitoxantrone plus prednisone for advanced prostate cancer. N Engl J Med 351: 1502-1512.

Tran C, Ouk S, Clegg NJ, Chen Y, Watson PA, Arora V, Wongvipat J, Smith-Jones PM, Yoo D, Kwon A, et al. 
2009. Development of a second-generation antiandrogen for treatment of advanced prostate cancer. Science 324: 787-790.

Tumeh PC, Harview CL, Yearley JH, Shintaku IP, Taylor EJM, Robert L, Chmielowski B, Spasic M, Henry G, Ciobanu V, et al. 2014. PD-1 blockade induces responses by inhibiting adaptive immune resistance. Nature 515: 568571.

Van Allen EM, Miao D, Schilling B, Shukla SA, Blank C, Zimmer L, Sucker A, Hillen U, Geukes Foppen MH, Goldinger SM, et al. 2015. Genomic correlates of response to CTLA4 blockade in metastatic melanoma. Science 350: 207-211.

van Soest RJ, de Morrée ES, Shen L, Tannock IF, Eisenberger MA, de Wit R. 2014. Initial biopsy Gleason score as a predictive marker for survival benefit in patients with castration-resistant prostate cancer treated with docetaxel: Data from the TAX327 study. Eur Urol 66: 330336.

Vrignaud P, Semiond D, Benning V, Beys E, Bouchard H, Gupta S. 2014. Preclinical profile of cabazitaxel. Drug Des Devel Ther 8: 1851-1867.

Welti J, Rodrigues DN, Sharp A, Sun S, Lorente D, Riisnaes R, Figueiredo I, Zafeiriou Z, Rescigno P, de Bono JS, et al. 2016. Analytical validation and clinical qualification of a new immunohistochemical assay for androgen receptor splice variant-7 protein expression in metastatic castration-resistant prostate cancer. Eur Urol 70: 599608.

Wissing MD, van Oort IM, Gerritsen WR, van den Eertwegh AJM, Coenen JLLM, Bergman AM, Gelderblom H. 2013a. Cabazitaxel in patients with metastatic castration-resistant prostate cancer: Results of a compassionate use program in the Netherlands. Clin Genitourin Cancer 11: 238-250.e1.

Wissing MD, van Leeuwen FWB, van der Pluijm G, Gelderblom H. 2013b. Radium-223 chloride: Extending life in prostate cancer patients by treating bone metastases. Clin Cancer Res 19: 5822-5827.

Yoshimoto M, Ludkovski O, DeGrace D, Williams JL, Evans A, Sircar K, Bismar TA, Nuin P, Squire JA. 2012. PTEN genomic deletions that characterize aggressive prostate cancer originate close to segmental duplications. Genes Chromosomes Cancer 51: 149-160.

Zhu ML, Kyprianou N. 2010. Role of androgens and the androgen receptor in epithelial-mesenchymal transition and invasion of prostate cancer cells. FASEB J 24: 769-777. 


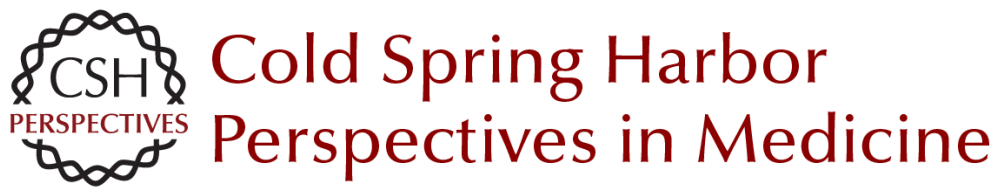

\title{
Treatment of Advanced Prostate Cancer-A Review of Current Therapies and Future Promise
}

\author{
Semini Sumanasuriya and Johann De Bono
}

Cold Spring Harb Perspect Med 2018; doi: 10.1101/cshperspect.a030635 originally published online November 3, 2017

\section{Subject Collection Prostate Cancer}

Anatomic and Molecular Imaging in Prostate

Cancer

Eric T. Miller, Amirali Salmasi and Robert E. Reiter

The Epidemiology of Prostate Cancer

Claire H. Pernar, Ericka M. Ebot, Kathryn M. Wilson, et al.

Prostate Stem Cells and Cancer Stem Cells Jia J. Li and Michael M. Shen

Prostate Cancer Epigenetics: From Basic Mechanisms to Clinical Implications Srinivasan Yegnasubramanian, Angelo M. De Marzo and William G. Nelson

The Genomics of Prostate Cancer: A Historic Perspective Mark A. Rubin and Francesca Demichelis

Neuroendocrine Differentiation in Prostate Cancer: Emerging Biology, Models, and Therapies Loredana Puca, Panagiotis J. Vlachostergios and Himisha Beltran

DNA Damage Response in Prostate Cancer Matthew J. Schiewer and Karen E. Knudsen

Transcriptional Regulation in Prostate Cancer David P. Labbé and Myles Brown
New Opportunities for Targeting the Androgen

Receptor in Prostate Cancer Margaret M. Centenera, Luke A. Selth, Esmaeil Ebrahimie, et al.

Prostate Cancer Research at the Crossroads Michael M. Shen and Mark A. Rubin

Immunotherapy for Prostate Cancer Nicholas J. Venturini and Charles G. Drake

Molecular Pathology of High-Grade Prostatic Intraepithelial Neoplasia: Challenges and Opportunities Levent Trabzonlu, Ibrahim Kulac, Qizhi Zheng, et al.

Metastases in Prostate Cancer Federico La Manna, Sofia Karkampouna, Eugenio Zoni, et al.

Genetically Engineered Mouse Models of Prostate Cancer in the Postgenomic Era Juan M. Arriaga and Cory Abate-Shen

Molecular Biomarkers in the Clinical Management of Prostate Cancer Aaron M. Udager and Scott A. Tomlins

Metabolic Vulnerabilities of Prostate Cancer: Diagnostic and Therapeutic Opportunities Giorgia Zadra and Massimo Loda

For additional articles in this collection, see http://perspectivesinmedicine.cshlp.org/cgi/collection/ 